\title{
Comparative Study of Korean White, Red, and Black Ginseng Extract on Cholinesterase Inhibitory Activity and Cholinergic Function
}

\author{
Mi Ra Lee ${ }^{1}$, Beom Sik Yun ${ }^{1}$, Oh Hyun In $^{2}$, and Chang Keun Sung ${ }^{1^{*}}$ \\ ${ }^{1}$ Department of Food Science and Technology, Chungnam National University, Daejeon 305-764, Korea \\ ${ }^{2}$ Korea Food Research Institute, Seongnam 463-764, Korea
}

\begin{abstract}
This study evaluated cholineresterase inhibitory activity of Korean white ginseng extract (WGE), red ginseng extract (RGE), and black ginseng extract (BGE) and the cholinergic effect on scopolamine (SCOP)-induced amnesic mice. WGE, RGE, and BGE inhibited acetylcholineserase (AChE), as well as butyrylcholineserase (BuChE) in a concentration-dependent manner. BGE presented strong inhibition of $\mathrm{AChE}$ with an $\mathrm{IC}_{50}$ value of $1.72 \mathrm{mg} / \mathrm{mL}$, followed by WGE $(5.89 \mathrm{mg} / \mathrm{mL}), \mathrm{RGE}(6.30 \mathrm{mg} / \mathrm{mL})$, respectively. The inhibitory activity of the three ginseng extracts on BuChE showed similar values among the groups. To better understand the mechanisms of the possible effect of ginseng extract on the cholinergic function, this study assessed the expression of the cholinergic markers of choline acetyltransferase (ChAT) and AChE using western blot and RT-PCR analysis in the brains of amnesic mice. Treatment with ginseng extracts led to inhibition of AChE expression and, the activation of ChAT expression in the hippocampus and the cerebral cortex of amnesic mice as induced by SCOP. The results suggest that ginseng extracts including $\mathrm{BGE}$, appear to modulate the metabolism of acetylchoine (ACh), which would greatly increase synaptic ACh levels and most potently revert SCOP-induced amnesia.
\end{abstract}

Keywords: Panax ginseng, Acetylcholinesterase, Butyrylcholinesterase, Scopolamine, Alzheimer disease

\section{INTRODUCTION}

Alzheimer's disease (AD) is a progressive neurodegenerative disorder characterized by deficits in cognitive function associated with an impaired cholinergic nervous system [1]. The cholinergic hypothesis states that a loss of the cholinergic function in the central nervous system (CNS) contributes significantly to the cognitive decline associated with advanced age and $\mathrm{AD}$ [2]. Scopolamine (SCOP), a blocker of muscarinic acetylcholine (ACh) receptor, induces a cognitive deficit in rodents and humans. The SCOP-induced memory deficit model is widely used to evaluate the effect of anti-amnesic drugs on learning ability in experimental animals [3]. ACh is an important

cC This is an Open Access article distributed under the terms of the Creative Commons Attribution Non-Commercial License (http://creativecommons.org/licenses/by-nc/3.0/) which permits unrestricted non-commercial use, distribution, and reproduction in any medium, provided the original work is properly cited. neurotransmitter that plays a critical role in memory and learning processes. In central cholinergic systems, ACh is synthesized from choline and acetyl-CoA by choline acetyltransferase (ChAT) [4]. After being delivered in the synapses, ACh is hydrolyzed, resulting in choline and an acetyl group in a reaction catalyzed by the enzyme cholinesterase (ChE) [5]. ChE is distinguished primarily by its substrate specificity. Acetylcholineserase (AChE) hydrolyzes ACh more efficiently than other choline esters, while butyrylcholinesterase $(\mathrm{BuChE})$ hydrolyzes mainly butyrylcholine $(\mathrm{BCh})$ among other types of $\mathrm{ACh}$. The molecular basis of the Alzheimer drugs used so far, takes

Received 01 Jul. 2011, Revised 26 Aug. 2011, Accepted 26 Aug. 2011

\footnotetext{
*Corresponding author

E-mail: kchsung@cnu.ac.kr

Tel: +82-42-821-6722, Fax: +82-42-822-2287
} 
advantage of their action as $\mathrm{ChE}$ inhibitors [6]. Because synthetic ChE inhibitors are limited in use due to their adverse side effects, such as gastrointestinal disturbances and bioavailability problems, there is still a need for the development of more potent agents, either natural products or synthetic analogues, with minimum side effects for the treatment of AD [7].

Ginseng (Panax ginseng Meyer, Araliaceae) has been used as a traditional herbal medicine for the treatment of many diseases in Asian countries. Ginseng saponins, known as ginsenosides, have been reported to have a number of effects in the CNS including stimulatory and depressive actions, anticonvulsant activity, analgesic activity, anti-fatigue activity, and enhanced cognitive performance [8]. Raw ginseng is processed into white ginseng $(W G)$ and red ginseng $(\mathrm{RG})$ to improve its preservation characteristics and efficacy. Black ginseng (BG) is a new type of processed ginseng produced from WG by nine cycles of steaming, at which point, the ginseng becomes black in color [9]. Studies of BG have shown that prolonged heat-treatment enhances the antioxidant activity with increased radical scavenging activity due to the release of phenolic compounds and Mailard reaction products during the heat processing stage [10].

Many studies have demonstrated that ginseng extract and single ginsenoside can be effective for the attenuation of learning deficits due to brain damage and ageing $[11,12]$. A previous study demonstrated that BG enhances cognitive activity in SCOP-induced amnesic mice [13]. However, the molecular mechanism of the cholinergic effect of BG in SCOP-induced amnesic mice has not been investigated.

Therefore, the present study compares the effect of WG, $R G$ and processed $B G$ on in vitro $\mathrm{ChE}$ inhibition. In addition, to evaluate whether the processed BG has a molecular mechanical effect on the cholinergic function, we examined the expression of protein levels and the mRNA levels of the cholinergic markers AChE and ChAT.

\section{MATERIALS AND METHODS}

\section{Preparation of ginseng extract}

Korean raw ginseng aged $4 \mathrm{y}$ was purchased from a local ginseng center (Geumsan, Korea). WG was produced by dehydration at $60^{\circ} \mathrm{C}$ in a dry oven. RG was made by steaming at $100^{\circ} \mathrm{C}$ for $2 \mathrm{~h}$ and drying at $60^{\circ} \mathrm{C}$. BG was made by steaming WG three times at $120^{\circ} \mathrm{C}$ for $30 \mathrm{~min}$ after soaking in grape juice for $24 \mathrm{~h}$ followed by drying at $60^{\circ} \mathrm{C}$ for $18 \mathrm{~h}$ as described by Sun [14]. To prepare the extracts, the ginseng was crushed into powder and ultrasonicated 3 times in 10 volumes of $80 \%$ ethanol at $50^{\circ} \mathrm{C}$ for $1 \mathrm{~h}$, and then it was filtered and lyophilized. The extraction yields of WG, RG, and BG were $36.02 \%$, $48.44 \%$ and $54.5 \%$, respectively.

\section{In vitro cholinesterase inhibitory activities}

ChE inhibitory activities were measured using the spectrophotometric method developed by Ellman et al. [15]. ACh and $\mathrm{BCh}$ were used as substrates to assay the inhibition of $\mathrm{AChE}$ and $\mathrm{BuChE}$, respectively. The assay mixture consisted of $340 \mu \mathrm{L}$ of $0.1 \mathrm{M}$ sodium phosphate buffer (pH 8.0), $40 \mu \mathrm{L}$ of $2 \mathrm{mM} \mathrm{5,} \mathrm{5'-dithiobis} \mathrm{(2-nitro-}$ benzoic acid) (DTNB), $40 \mu \mathrm{L}$ of the sample, and $460 \mu \mathrm{L}$ of either $\mathrm{AChE}$ or $\mathrm{BuChE}(0.22 \mathrm{U} / \mathrm{mL})$ prepared in 50 $\mathrm{mM}$ Tris buffer $(\mathrm{pH} 8.0)$ containing $0.1 \%$ bovine serum albumin. After $10 \mathrm{~min}$, the reactions were initiated with the addition of $10 \mu \mathrm{L}$ of either $3.75 \mathrm{mM}$ acetylthiocholine iodide (ATCI) or $3.75 \mathrm{mM}$ butyrylthiocholine chloride (BTCC) to the solution. The hydrolysis of ATCI or BTCC was monitored by following the formation of yellow 5-thio-2-nitrobenzoate anion at $410 \mathrm{~nm}$ for $2 \mathrm{~min}$, which resulted from the reaction of DTNB with thiocholine, which was released by the enzymatic hydrolysis of either ATCI or BTCC, respectively.

The inhibition percentage was calculated from $\left[\mathrm{A}_{0}-\right.$ $\left.A_{1} / A_{0}\right] \times 100$, where $A_{0}$ is the change in absorbance of the control and $A_{1}$ is the change in absorbance in the presence of the test compound. The $\mathrm{ChE}$ inhibitory activities of each sample were expressed in terms of the $\mathrm{IC}_{50}$ value $(\mathrm{mg} / \mathrm{mL}$ required to inhibit the hydrolysis of the substrate; ATCI or BTCC, by $50 \%$ ).

\section{Animals}

ICR mice (10 weeks old, weighing 20 to $25 \mathrm{~g}$ ) were purchased from the DaeHan Biolink (Eumseong, Korea). The mice were housed individually in cages, allowed access to water and food ad libitum, and maintained in an environment of constant temperature $\left(22 \pm 1^{\circ} \mathrm{C}\right)$ and humidity ( $50 \%$ to $55 \%)$ under a $12 \mathrm{~h} \mathrm{light/dark} \mathrm{cycle}$ (light on at 08:00). All the experimental procedures were carried out in accordance with the NIH Guide for Care (NIH publication no. 85-23, 1985, revised 1996) and were approved by the Institutional Animal Care and Use Committee at Chungnam National University.

\section{Administration of drugs}

To determine the dose of ginseng extract, the effect of a single administration of black ginseng extract (BGE) on retention latency was carried out using passive avoidance test in SCOP-induced memory impaired mice. The 
animals were randomly divided into the following groups with 10 mice in each: control (0.9\% saline), SCOP (2 $\mathrm{mg} / \mathrm{kg}$, i.p.), tacrine (THA, $10 \mathrm{mg} / \mathrm{kg}$, p.o.)+SCOP, and BGE (50 to $500 \mathrm{mg} / \mathrm{kg}$, p.o)+SCOP. The control animals were administered with a vehicle solution only. SCOP was injected to produce learning and memory deficits 30 min after the administration of each drug or vehicle solution. SCOP, THA, and BGE were dissolved in $0.9 \%$ physiological saline.

\section{Treatments}

Animals were randomly divided into the following groups with 10 mice in each: control (0.9\% saline), SCOP (2 mg/kg, i.p.), THA (10 mg/kg, p.o.)+SCOP, white ginseng extract (WGE)+SCOP (200 mg/kg, p.o.), red ginseng extract (RGE)+SCOP (200 mg/kg, p.o.), and BGE (200 mg/kg, p.o)+SCOP. Control animals were administered with a vehicle solution only. SCOP, THA, WGE and BGE were dissolved in $0.9 \%$ physiological saline. All mice except the control group received SCOP ( $2 \mathrm{mg} / \mathrm{kg}$, i.p.) for one wk.

\section{Passive avoidance test}

A passive avoidance test was carried out using a passive avoidance apparatus (Jungdo Bio \& Plant, Seoul, Korea) to find the appropriate dose within several doses for the in vivo experiment. This apparatus comprises of 2 equal compartments $(20 \times 20 \times 20 \mathrm{~cm})$ separated by a guillotine door $(5 \times 5 \mathrm{~cm})$. For the acquisition trial, mice were initially placed in the illuminated compartment and the door between the two compartments was opened 20 $\mathrm{s}$ later. When the mice entered the dark compartment, the door was closed and an electrical foot shock $(0.5 \mathrm{~mA}$ for $3 \mathrm{~s}$ ) was delivered through the stainless steel rods. On the second day, the same procedure was carried out. Mice were again placed in the illuminated compartment to test retention. The time for a mouse to enter the dark compartment after the door opened was defined as latency. If a mouse did not enter the dark compartment within 300 $\mathrm{s}$, it was assumed that the mouse had remembered the single 'acquisition' trial experience.

\section{Western blot analysis}

Protein was extracted from the cerebral cortex and hippocampus with a protein extraction buffer (PRO-PREP ${ }^{\mathrm{TM}}$; iNtRON Biotechnology, Seongnam, Korea). Lysates were centrifuged for $20 \mathrm{~min}$ at $10,000 \times \mathrm{g}$ at $4{ }^{\circ} \mathrm{C}$ and protein levels in the supernatant were determined by the Bradford assay. The samples were adjusted to a concentration of $2 \mu \mathrm{L} / \mathrm{mL}$. Samples $(20 \mu \mathrm{g})$ were loaded in $10 \%$ sodium dodecyl sulfate-polyacrylamide gel electrophoresis and transferred to an immobilon polyvinylidene fluoride transfer membrane $(0.45 \mu \mathrm{m}$; Millipore, MA, USA). The membrane was blocked with $5 \%$ non-fat milk in $1 \times$ Tris-buffered saline containing $0.1 \%$ Tween 20 overnight at $4^{\circ} \mathrm{C}$. The membranes were incubated overnight at $4^{\circ} \mathrm{C}$ with primary antibodies followed by polyclonal rabbit anti-ChAT (1:300; Santa Cruz, CA, USA), polyclonal rabbit anti-AChE (1:200, Santa Cruz), and polyclonal goat anti- $\beta$-Actin (1:1000, Santa Cruz). Detection of specific binding was performed by incubation with HRPconjugated secondary antibodies (1:4000, Santa Cruz). Blots were detected using an ECL plus immunoblotting detection kit (WEST-ne ${ }^{\mathrm{TM}}$, iNtRON Biotechnology). Band intensities were analyzed by Quantity One ${ }^{\circledR}$ 1-D analysis software (Bio-Rad, Hercules, CA, USA).

\section{RNA extraction and RT-PCR}

Total RNA was extracted from the cerebral cortex and hippocampus using Trizol reagent (Invitrogen, Carlsbad, CA, USA). RNA concentration and quality were assessed based on $260 \mathrm{~nm} / 280 \mathrm{~nm}$ absorbance ratios. For cDNA synthesis, $1 \mu \mathrm{g}$ of total RNA was reversed-transcribed using Maxime ${ }^{\mathrm{TM}}$ RT PreMix Kit (Oligo (dT)15 Primer, iNtRON Biotechnology) in a final volume of 20 $\mu \mathrm{L}$ according to the protocol of the manufacturers. Using a thermal cycler (Bio-Rad iCycler, Bio-Rad), PCR was performed in a $20 \mu \mathrm{L}$ reaction mixture that contained $2.5 \mathrm{mM}$ dNTPs, and $2.5 \mathrm{U}$ of $i$-Taq DNA polymerase in a buffer supplied by the manufacturer (Maxime ${ }^{\mathrm{TM}} \mathrm{PCR}$ PreMix, iNtRON Biotechnology) with $0.2 \mu \mathrm{M}$ of each primer. The sequences of the primers and their predicted sizes are given in Table 1 and are based on previous reports $[16,17]$. The amplification protocol entailed 30 to 35 cycles of denaturation at $94^{\circ} \mathrm{C}$ for $30 \mathrm{~s}$, annealing at $60^{\circ} \mathrm{C}$ to $64^{\circ} \mathrm{C}$ for $30 \mathrm{~s}$ and extension at $72^{\circ} \mathrm{C}$ for $1 \mathrm{~min}$, followed by a $5 \mathrm{~min}$ final extension at $72^{\circ} \mathrm{C}$. As an internal control, $\beta$-actin mRNA expression was also evaluated. PCR products present in $20 \mu \mathrm{L}$ of the reaction mixture were separated on a $1.2 \%$ agarose gel, stained with RedSafe ${ }^{\mathrm{TM}}$ Nucleic acid staining solution (iNtRON Biotechnology), and visualized under UV light.

\section{Statistical analysis}

All the results were expressed as mean \pm SD. The data were analyzed by one-way ANOVA followed by Duncan's test to determine where differences among groups existed. A difference of $p<0.05$ was considered significant. 
Table 1. Primers and the predicted sizes used for RT-PCR

\begin{tabular}{llc}
\hline \multicolumn{1}{c}{ Gene } & \multicolumn{1}{c}{ Sequences $\left(5^{\prime} \rightarrow 3^{\prime}\right)$} & Size (bp) \\
\hline \multirow{2}{*}{ Acetylcholineserase } & F-GAC TGC CTT TAT CTT AAT GTG & 785 \\
& R-CGG CTG ATG AGA GAT TCA TTG & 473 \\
Choline acetyltransferase & F-GAC AAG ACA GCC AAT TGG GTC & 505 \\
\multirow{2}{*}{$\beta$-actin } & R-TTC ATC CTC GTT GGA CGC CAT & 5 \\
\hline
\end{tabular}

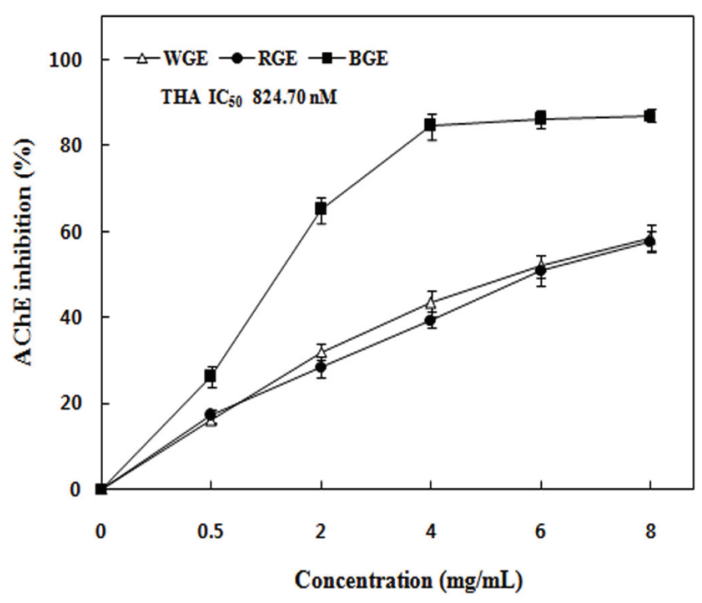

Fig. 1. Effect on acetylcholineserase (AChE) inhibitory activities in relation to various concentrations of three types of ginseng extracts. WGE, white ginseng extract; RGE, red ginseng extract; BGE, black ginseng extract; THA, tacrine. Results are expressed as Mean \pm SD $(n=3)$.

\section{RESULTS}

\section{In vitro cholinesterase inhibition}

The inhibitory activities of the three ginseng extracts on $\mathrm{AChE}$ and $\mathrm{BuChE}$ were evaluated and the inhibition percentages are shown in Figs. 1 and 2. The results revealed that ginseng extracts inhibit $\mathrm{ChE}$ in a dosedependent manner. The $\mathrm{IC}_{50}$ values of $\mathrm{ChE}$ inhibition for the ginseng extracts are shown in Table 2. According to the results obtained, BGE displayed the highest level of inhibition towards $\mathrm{AChE}$ in terms of the concentration manner, at $25.67 \pm 0.71 \%, 64.98 \pm 3.56 \%, 84.28 \pm 2.18 \%$, and $95.47 \pm 1.20 \%$ of inhibition at $0.5,2,4,6$, and $8 \mathrm{mg} /$ $\mathrm{mL}$, respectively. The $\mathrm{IC}_{50}$ values of $\mathrm{AChE}$ for WGE, RGE, and BGE were $5.89 \mathrm{mg} / \mathrm{mL}, 6.30 \mathrm{mg} / \mathrm{mL}$, and 1.72 $\mathrm{mg} / \mathrm{mL}$, respectively. The $\mathrm{IC}_{50}$ value of THA (positive control) was $824.70 \mathrm{nM}$. The inhibitory effects of the ginseng extracts on the $\mathrm{BuChE}$ activity showed similar values among the groups. The $\mathrm{IC}_{50}$ values of $\mathrm{BuChE}$ for WGE, RGE and BGE were $2.56 \mathrm{mg} / \mathrm{mL}, 1.84 \mathrm{mg} / \mathrm{mL}$, and $1.88 \mathrm{mg} / \mathrm{mL}$, respectively. The $\mathrm{IC}_{50}$ value of THA (positive control) of BuChE was $394.45 \mathrm{nM}$.

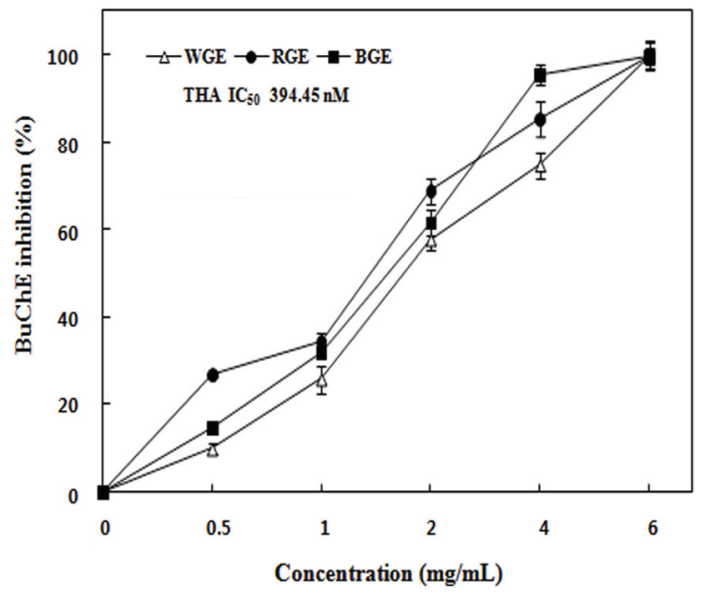

Fig. 2. Effect on butyrylcholinesterase (BuChE) inhibitory activities in relation to various concentrations of three types of ginseng extracts. WGE, white ginseng extract; RGE, red ginseng extract; BGE, black ginseng extract; THA, tacrine. Results are expressed as Mean \pm SD $(n=3)$.

Table 2. $I_{50}$ values of ginseng extracts on AChE and BChE

\begin{tabular}{lrr}
\hline \multirow{2}{*}{ Ginseng extracts } & \multicolumn{2}{c}{$\mathrm{IC}_{50}(\mathrm{mg} / \mathrm{mL})$} \\
\cline { 2 - 3 } & $\mathrm{AChE}$ & $\mathrm{BChE}$ \\
\hline WGE & 5.89 & 2.56 \\
RGE & 6.30 & 1.84 \\
BGE & 1.72 & 1.88 \\
THA (nM) & 824.70 & 394.45 \\
\hline
\end{tabular}

Values are expressed as mean \pm SD $(n=3)$.

AChE, acetylcholineserase; BuChE, butyrylcholinesterase; WGE, white ginseng extract; RGE, red ginseng extract; $B G E$, black ginseng extract; THA, tacrine.

\section{Passive avoidance test}

As shown in Fig. 3, the step-through latency of SCOPtreated mice was significantly shorter than that of the vehicle-treated control group $(p<0.001)$. A single oral administration of BGE with a dose between 50 and 500 $\mathrm{mg} / \mathrm{kg}$ reversed the shorter step-through latency induced by SCOP. Furthermore, the step-through latency of mice treated with 100 and $200 \mathrm{mg} / \mathrm{kg}$ BGE was significantly increased compared to that of the SCOP-treated mice ( $77.87 \%$ and $87.97 \%$ of control, $p<0.01$, respectively). 


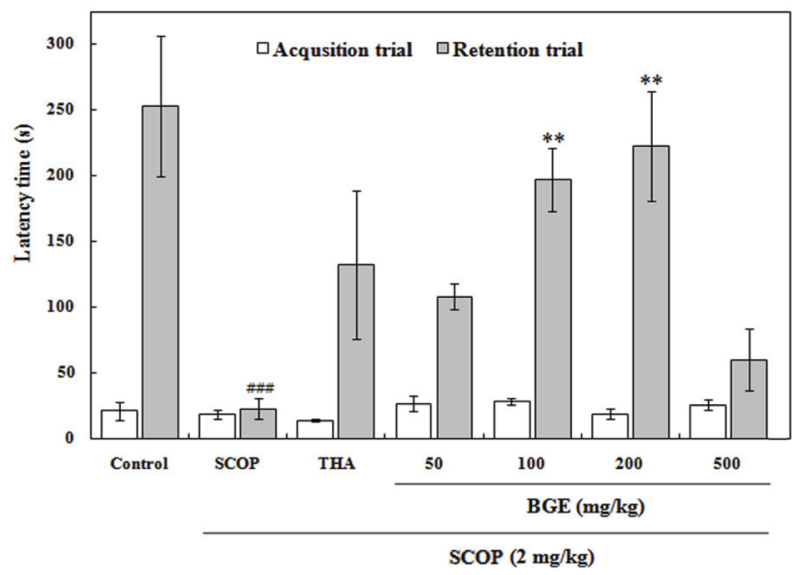

Fig. 3. Effect of a single administration of black ginseng extract (BGE) on scopolamine (SCOP)-induced memory deficits in the passive avoidance task. THA, tacrine. " $p<0.01$ vs. SCOP group, $p<0.001$ vs. control group.
Additionally, the dose of $200 \mathrm{mg} / \mathrm{kg}$ BGE was not only more effective, but it also had a higher potency than that of the THA-treated group ( $43.8 \%$ of control). Finally, the dose of $200 \mathrm{mg} / \mathrm{kg}$ BGE was the most efficacious dose, so we chose this dose to continue administration for the cholinergic function.

\section{Western blot analysis}

Western blot analysis of the cholinergic markers ChAT and $\mathrm{AChE}$ in the hippocampus (A) and in the cerebral cortex (B) are shown in Fig. 4. The results reveal an increase in the ChAT levels in the ginseng-treated groups in the hippocampus and in the cerebral cortex compared to that of the SCOP group $(p<0.001)$. Moreover, the increased efficacy of the ChAT levels in the groups treated with ginseng extract were higher than those of the THA group in the cerebral cortex. However, in the SCOP
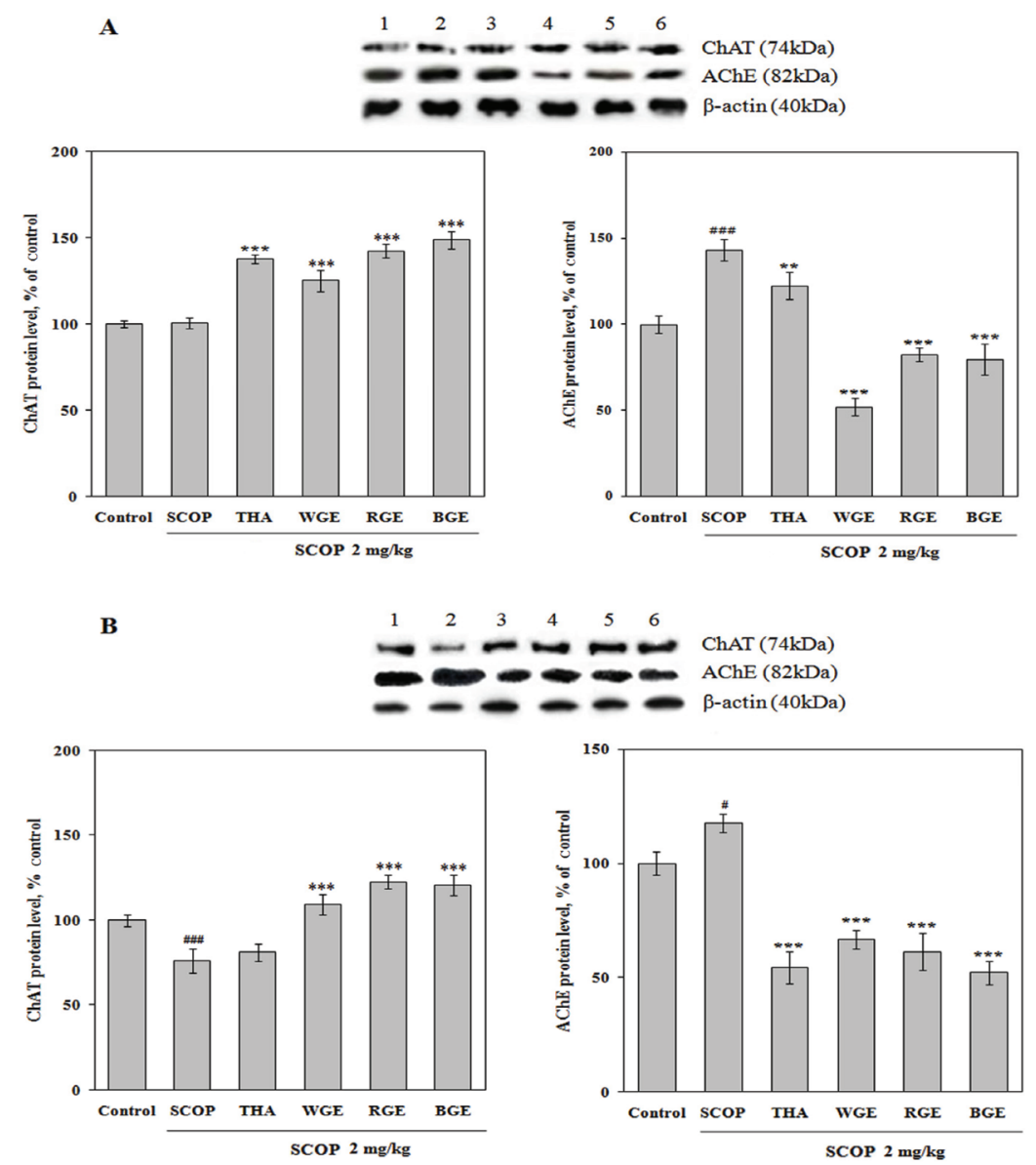

Fig. 4. Western blot analysis of the cholinergic marker proteins in the hippocampus (A) and cerebral cortex (B) of scopolamine (SCOP)-induced amnesic mice. Lane 1, vehicle-treated control group; lane 2, SCOP-treated group; lane 3, tacrine (THA)+SCOP group; lane 4, white ginseng extract (WGE)+SCOP group; lane 5, red ginseng extract (RGE)+SCOP group; lane 6, black ginseng extract (BGE)+SCOP group. $\beta$-Actin was used as an internal control for protein expression. ChAT, choline acetyltransferase; AChE, acetylcholineserase. ${ }^{\#} p<0.05,{ }^{\# \#} p<0.001$ compared with control group. " $p<0.01, "=p<0.001$ comapred with SCOP group. 
group, the hippocampal ChAT levels showed no change, and the cortical ChAT levels decreased to $76.1 \%$ compared to the control group $(p<0.001)$. The administration of SCOP significantly increased the AChE levels compared to the control group in the hippocampus (143.2\%, $p<0.001)$ and cerebral cortex $(117.9 \%, p<0.05)$. The hippocampal AChE levels increased by SCOP were inhibited by the ginseng extracts of WGE, RGE, and BGE $(51.8 \%, 82.3 \%$, and $79.5 \%$ of the control values, $p<0.001$, respectively). The inhibitory effects of ginseng extracts on the AChE levels were higher than that of the THA group as a positive control (122.5\% of the control values). Consistent with the hippocampal AChE levels, the AChE levels increased by SCOP in the cerebral cortex were inhibited by THA ( $53.4 \%$ of control, $p<0.001)$ or ginseng extracts (WGE, RGE, and BGE, at $66.8 \%$, $61.3 \%, 52.1 \%$ of the control group; $p<0.001$, respectively).

\section{RT-PCR}

The expression of mRNA levels for ChAT and AChE were investigated using RT-PCR (Fig. 5). The ChAT mRNA levels were decreased by the administration of SCOP in the hippocampus $(72.7 \%, p<0.001)$ and cerebral cortex $(78.2 \%, p<0.05)$ as compared to the control group. THA or BGE treatment did not affect the expression of ChAT mRNA in the hippocampus. However, the WGEand RGE-treated groups recovered their hippocampal ChAT mRNA levels as decreased by SCOP $(91.2 \%$ and $88.3 \%, p<0.01$, respectively). In the cerebral cortex, the ChAT mRNA levels did not change after treatment with THA or ginseng extracts.

The AChE mRNA levels increased by SCOP in the cerebral cortex (140.6\% of the control group, $p<0.01$ ); however, in the hippocampus, these values did not changed. The increased AChE mRNA levels were inhibited by THA or ginseng extracts in the cerebral cortex

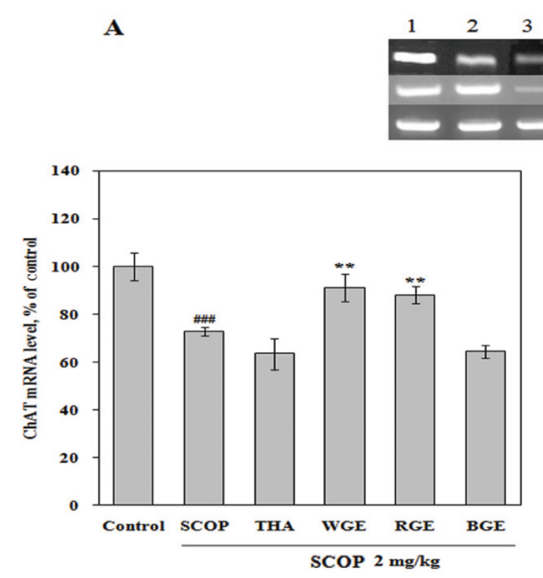

\section{B}

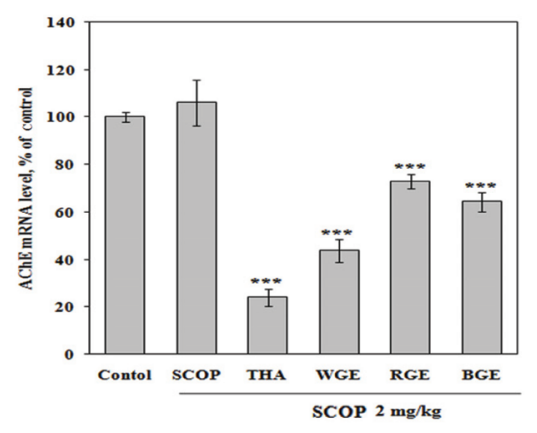

$12 \quad 2 \quad 3 \quad 5 \quad 6$
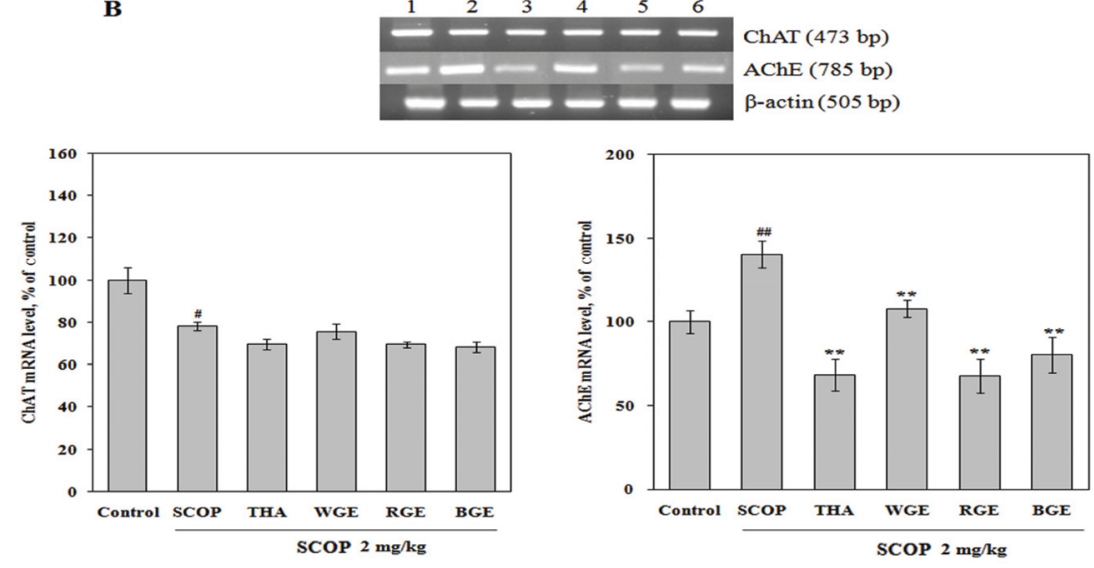

Fig. 5. RT-PCR of the cholinergic marker genes in the hippocampus (A) and cerebral cortex (B) of amnesic mice induced by scopolamine (SCOP). Lane 1, vehicle-treated control group; lane 2, SCOP-treated group; lane 3, tacrine (THA)+SCOP group; lane 4, white ginseng extract (WGE)+SCOP group; lane 5, red ginseng extract (RGE)+SCOP group; lane 6, black ginseng extract (BGE)+SCOP group. $\beta$-actin was used as an internal control for protein expression. ChAT, choline acetyltransferase; AChE, acetylcholineserase. ${ }^{\#} p<0.05,{ }^{\#} p<0.01,{ }^{\# \#} p<0.001$ compared with control group. " $p<0.01, "=0<001$ comapred with SCOP group. 
and hippocampus to a level lower than that of the control group.

\section{DISCUSSION}

Abnormality of the cholinergic system in the senile dementia symptoms of AD is indicated by biochemical observations that the true cholinesterase (AChE) enzyme is substantially reduced, whereas pseudo-cholinesterase (BuChE) is increased in the cerebral cortex $[18,19]$. Selective BuChE inhibitors could be used to treat more severe cases of $\mathrm{AD}$ by elevating the extracellular levels of cortical ACh without producing relevant side effects. Moreover, they may represent an additional advantage for the long-term stabilization of cognitive and behavioral symptoms in patients with advanced AD [20]. Plant extracts, which have dual anti-ChE activity, may be appropriate for patients at a moderate stage of AD [21]. This study indicates that, of the ginseng extracts for antiChE activity, RGE and BGE show the highest inhibitory activity for both types of $\mathrm{ChE}$. Therefore, the effectiveness of ginseng extracts against memory loss may result from the cholinergic activity of these extract via reduction of the degradation rate of ACh by inhibition of the ChE activity.

To understand the underlying mechanism of the possible effect of ginseng extracts on increasing the cholinergic transmission, this study assessed the expression of the cholinergic markers of ChAT and AChE using western blot and RT-PCR analysis. ChAT, the biosynthetic enzyme for $\mathrm{ACh}$, is presently the most specific cholinergic marker for checking the functional state of cholinergic neurons in the CNS. A reduction of ChAT activity can lead to a loss of ChAT-producing cholinergic neurons [22]. The present study has shown that the ChAT mRNA levels in the SCOP group decreased considerably compared to those of the control group, both in the cerebral cortex and the hippocampus. Our results are in agreement with those of a recent study by Oh et al. [23], which demonstrated that ChAT-positive neurons in the medial septum were significantly reduced by treatment with SCOP when compared to those of a vehicle-treated control group. However, further research is needed to clarify the exact mechanism in the region of the brain.

Systematic administration of SCOP as a cholinergic receptor antagonist obstructs cholinergic neurotransmission, leading to an increase in $\mathrm{AChE}$ and causing a cognitive deficit [24]. In the present study, the ginsengtreated groups showed a reduction in the increased $\mathrm{AChE}$ expression of protein and mRNA both in the cerebral cortex and the hippocampus. We also demonstrated that treatment of SCOP-induced amnesic mice with ginseng extracts of WGE, RGE, and BGE inhibited the increased AChE enzyme activity produced by SCOP and increased ChAT activity by different mechanisms [13]. Treatment with ginseng extracts showed significant inhibition of AChE expression as well as the activation of ChAT expression in the cerebral cortex and the hippocampus of SCOP-induced amnesic mice. Because ACh is an important neurotransmitter that plays a critical role in memory and in the learning process, $\mathrm{AChE}$ inhibition and ChAT activation may offset reduction of the ACh levels in the brain found in $\mathrm{AD}$. Therefore, ginseng extracts, including BGE appear to both increase ACh synthesis and inhibit ACh degradation, which would greatly increase synaptic ACh levels and most potently reverse SCOP-induced amnesia.

\section{ACKNOWLEDGEMENTS}

This study was supported by Technology Development Program for Food, Ministry for Food, Agriculture, Forestry and Fisheries, Korea.

\section{REFERENCES}

1. Birthelmer A, Lazaris A, Riegert C, Marques Pereira P, Koenig J, Jeltsch H, Jackisch R, Cassel JC. Does the release of acetylcholine in septal slices originate from intrinsic cholinergic neurons bearing p75(NTR) receptors? A study using 192 IgG-saporin lesions in rats. Neuroscience 2003;122:1059-1071.

2. Bartus RT. On neurodegenerative diseases, models, and treatment strategies: lessons learned and lessons forgotten a generation following the cholinergic hypothesis. Exp Neurol 2000;163:495-529.

3. Beatty WW, Butters N, Janowsky DS. Patterns of memory failure after scopolamine treatment: implications for cholinergic hypotheses of dementia. Behav Neural Biol 1986;45:196-211.

4. Ohno K, Tsujino A, Brengman JM, Harper CM, Bajzer Z, Udd B, Beyring R, Robb S, Kirkham FJ, Engel AG. Choline acetyltransferase mutations cause myasthenic syndrome associated with episodic apnea in humans. Proc Natl Acad Sci U S A 2001;98:2017-2022.

5. Ballard CG, Greig NH, Guillozet-Bongaarts AL, Enz A, Darvesh S. Cholinesterases: roles in the brain during health and disease. Curr Alzheimer Res 2005;2:307-318.

6. Heinrich M, Lee Teoh H. Galanthamine from snowdrop: the development of a modern drug against Alzheimer's 
disease from local Caucasian knowledge. J Ethnopharmacol 2004;92:147-162.

7. Melzer D. New drug treatment for Alzheimer's disease: lessons for healthcare policy. BMJ 1998;316:762-764.

8. Attele AS, Wu JA, Yuan CS. Ginseng pharmacology: multiple constituents and multiple actions. Biochem Pharmacol 1999;58:1685-1693.

9. Sun BS, Gu LJ, Fang ZM, Wang CY, Wang Z, Sung CK. Determination of 11 ginsenosides in black ginseng developed from Panax ginseng by high performance liquid chromatography. Food Sci Biotechnol 2009;18:561-564.

10. Kang KS, Yamabe N, Kim HY, Okamoto T, Sei Y, Yokozawa $\mathrm{T}$. Increase in the free radical scavenging activities of American ginseng by heat processing and its safety evaluation. J Ethnopharmacol 2007;113:225-232.

11. Nitta H, Matsumoto K, Shimizu M, Ni XH, Watanabe H. Panax ginseng extract improves the scopolamine-induced disruption of 8-arm radial maze performance in rats. Biol Pharm Bull 1995;18:1439-1442.

12. Yamaguchi Y, Higashi M, Kobayashi H. Effects of ginsenosides on maze performance and brain choline acetyltransferase activity in scopolamine-treated young rats and aged rats. Eur J Pharmacol 1997;329:37-41.

13. Lee MR, Yun BS, Lui L, Zhang DL, Wang Z, Wang CL, Gu LJ, Wang CY, Mo EK, Sung CK. Effect of black ginseng on memory improvement in the amnesic mice induced by scopolamine. J Ginseng Res 2010;34:51-58.

14. Sun BS. Bioconversion to rare ginsenoside and memory and learning functions of white, red, and black ginsengs [dissertation]. Daejeon: Chungnam National University, 2009.

15. Ellman GL, Courtney KD, Andres V Jr, Feather-Stone RM. A new and rapid colormetric determination of ace- tylcholinesterase activity. Biochem Pharmacol 1961;7:8895.

16. Jamal M, Ameno K, Ameno S, Morishita J, Wang W, Kumihashi M, Ikuo U, Miki T, Ijiri I. Changes in cholinergic function in the frontal cortex and hippocampus of rat exposed to ethanol and acetaldehyde. Neuroscience 2007; 144:232-238.

17. Cederberg J, Galli J, Luthman H, Eriksson UJ. Increased mRNA levels of Mn-SOD and catalase in embryos of diabetic rats from a malformation-resistant strain. Diabetes 2000;49:101-107.

18. Davies P, Maloney AJ. Selective loss of central cholinergic neurons in Alzheimer's disease. Lancet 1976;2:1403.

19. Op den Velde W, Stam FC. Some cerebral proteins and enzyme systems in Alzheimer's presenile and senile dementia. J Am Geriatr Soc 1976;24:12-16.

20. Giacobini E. Selective inhibitors of butyrylcholinesterase: a valid alternative for therapy of Alzheimer's disease? Drugs Aging 2001;18:891-898.

21. Giacobini E. Cholinesterases: new roles in brain function and in Alzheimer's disease. Neurochem Res 2003;28:515522.

22. Oda Y. Choline acetyltransferase: the structure, distribution and pathologic changes in the central nervous system. Pathol Int 1999;49:921-937.

23. Oh JH, Choi BJ, Chang MS, Park SK. Nelumbo nucifera semen extract improves memory in rats with scopolamine-induced amnesia through the induction of choline acetyltransferase expression. Neurosci Lett 2009;461:4144.

24. Levey AI. Muscarinic acetylcholine receptor expression in memory circuits: implications for treatment of Alzheimer disease. Proc Natl Acad Sci U S A 1996;93:13541-13546. 